\title{
Determination of higher carboxylic acids in snow samples using solid-phase extraction and LC/MS-TOF
}

\author{
Matthias Kippenberger • Richard Winterhalter • \\ Geert K. Moortgat
}

Received: 6 May 2008 /Revised: 18 September 2008 / Accepted: 25 September 2008 / Published online: 29 October 2008

(C) The Author(s) 2008. This article is published with open access at Springerlink.com

\begin{abstract}
The objective of this work was to develop a method to determine the concentrations of higher organic acids in snow samples. The target species are the homologous aliphatic $\alpha, \omega$-dicarboxylic acids from $\mathrm{C}_{5}$ to $\mathrm{C}_{13}$, pinonic acid, pinic acid and phthalic acid. A preconcentration procedure utilizing solid phase extraction was developed and optimized using solutions of authentic standards. The influences of different parameters such as flow rate during extraction and the concentration of the eluent on the efficiency of the extraction procedure were investigated. The compounds of interest were separated by HPLC and detected by a quadrupole time-of-flight mass spectrometer (qTOF-MS). The recovery rate (extraction efficiency) of the extraction procedure was found to vary between $41 \%$ for tridecanedioic acid and $102 \%$ for adipic acid. The limits of detection were determined for all compounds and were between $0.9 \mathrm{nmol} / \mathrm{L}$ (dodecanedioic acid) and $29.5 \mathrm{nmol} / \mathrm{L}$ (pinonic acid). An exception is pinic acid, for which a considerably higher detection limit of $103.9 \mathrm{nmol} / \mathrm{L}$ was calculated. Snow samples were collected in December 2006 and January 2007 at the Fee glacier (Switzerland) from locations at heights from 3056 to $3580 \mathrm{~m}$ asl and from different depths within the snow layer. In total, the analysis of 61 single snow samples was performed, and the following compounds could be quantified: homologous aliphatic $\alpha, \omega-$ dicarboxylic acids with 5-12 carbon atoms and phthalic acid. Tridecanedioic acid, pinonic and pinic acid were identified in the samples but were not quantified due to their low concentrations. The three most abundant acids found in the molten
\end{abstract}

M. Kippenberger $\cdot$ R. Winterhalter $(\bowtie) \cdot G$. K. Moortgat Atmospheric Chemistry Division,

Max Planck Institute for Chemistry,

P.O. Box, 3060, 55020 Mainz, Germany

e-mail: winterha@mpch-mainz.mpg.de snow samples were glutaric acid $\left(\mathrm{C}_{5}\right.$-di; $\left.3.90 \mathrm{nmol} / \mathrm{L}\right)$, adipic acid $\left(\mathrm{C}_{6}\right.$-di; $\left.3.35 \mathrm{nmol} / \mathrm{L}\right)$ and phthalic acid $(\mathrm{Ph}$; $3.04 \mathrm{nmol} / \mathrm{L})$.

Keywords Dicarboxylic acids · Snow samples · Solid-phase extraction $\cdot$ Pinonic acid $\cdot$ Phthalic acid $\cdot$ Fee glacier

\section{Introduction}

Atmospheric aerosol particles are known to contain organic carbon material in variable amounts depending on their location. In some parts of the world, organic compounds make up the majority of the total suspended particle mass [1-3]. Dicarboxylic acids are among the most abundant contributors to organic carbon and are thus main constituents of the atmospheric aerosol mass $[4,5]$. Due to their low vapor pressure [6], dicarboxylic acids are predominantly present in the condensed phase, such as in rain, clouds or in aerosol particles [7-10]. They are ubiquitous in the atmosphere; measurements are reported from urban [11-15], continental background [16-19], remote marine [20-24] and polar aerosols [25, 26].

They have also been observed in snow samples [27]. In Arctic snow samples, oxalic acid is usually most abundant, followed by malonic, succinic and glutaric acid [28]. However, in snow samples collected in urban environments (Tokyo), succinic, azelaic or phthalic acid were found as the second most abundant acids after oxalic acid [29]. The total mass of the observed dicarboxylic acids can vary over a few days, with differences in concentration of up to an order of magnitude observed $[28,30]$.

The concentrations and relative abundances of dicarboxylic acids are controlled by primary sources and secondary formation through photooxidation processes. Direct emissions 
originate from fossil fuel combustion [31, 32], biomass burning [33-37] and sources such as meat cooking [38]. Secondary sources include the photooxidation of unsaturated fatty aids [22, 39] and cyclic alkenes [40]. The relative contributions of these sources and their temporal and spatial variabilities are still unclear [21]. A recent model study for the North Pacific implies that $\mathrm{C}_{2}-\mathrm{C}_{7}$ dicarboxylic acids are of anthropogenic origin, whereas $\mathrm{C}_{8}-\mathrm{C}_{11}$ species may be of natural origin, and are possibly emitted from the ocean [21]. Carboxylic acids are also constituents of biogenically emitted compounds such as terpenes forming secondary organic aerosols (SOAs) [41]. Photochemical oxidation studies of the monoterpenes $\alpha$ - and $\beta$-pinene have shown to produce lowvolatile acids as such as pinic and pinonic acid [42-51].

Atmospheric aerosol plays a key role in the radiative budget of the Earth's atmosphere, directly by absorbing and scattering of radiation and indirectly through the formation of cloud condensation nuclei (CCN) [52, 53]. Dicarboxylic acids may be important contributors to the activation of aerosol particles to $\mathrm{CCN}[54,55]$. Laboratory experiments have shown that particles containing dicarboxylic acids demonstrate similar $\mathrm{CCN}$ activity to sulfate particles [56, 57]. However, for aliphatic saturated dicarboxylic acids, the CCN activity decreases with their water solubility and chain length [58]. On the other hand, it has been shown that for phthalic acid the $\mathrm{CCN}$ activity is similar to that for malic acid, although phthalic acid is not very soluble [59].

Moreover, dicarboxylic acids may play a decisive role in ice nuclei formation [60], even if their mass fraction of the total organic aerosol is of only $2-4 \%$ [4]. It has been shown in laboratory experiments that oxalic acid forms heterogeneous ice nuclei [60], while higher dicarboxylic acids instead inhibit ice nucleation [56]. The identification and quantification of dicarboxylic acids in fresh snow samples is an initial step towards understanding their possible role in ice nucleation processes.

The objective of this paper is to report on the qualitative and quantitative analysis of dicarboxylic acids in snow samples. The development of the complete analytical method includes a number of steps such as snow collection and storage, sample preparation, isolation of the analytes, their identification, and finally quantification. The method describes the preconcentration of the collected snow samples using solid-phase extraction followed by identification by LC/MS-TOF.

\section{Experimental}

Background information on SPE

Solid-phase extraction (SPE) was introduced in the early 1970s and offers a magnitude of advantages over the more frequently used liquid-liquid extraction (LLE), where especially the lack of availability of large volumes of ultrapure organic solvents has been found to be a major disadvantage [61]. SPE is particularly well adapted to handling large water samples and is preferentially used for the removal of interfering compounds using appropriate washing solvents. Trace organic compounds are retained on the appropriate sorbent while the water passes through, and they are later recovered by elution with a small volume of (in)organic solvent [62]. SPE is a simple LC process and involves the partitioning of the analytes to be extracted between a solid and a liquid phase. These analytes must have a greater affinity for the solid phase than for the sample matrix (adsorption or retention step). The compounds retained on the solid phase (sorbent) can be removed at a later stage by eluting with a solvent with a greater affinity for the analytes (desorption or elution step).

In modern SPE, the sorbent is packed between two fritted disks positioned in cartridges made of glass or polypropylene. The elution solvent is passed through the cartridge by gas pressure or gravity, or sucked by means of a small membrane pump or syringe. Different sorbent materials for SPE can be used depending on the chemical nature of the analytes, such as octadecyl- or octylbonded silica, porous styrene-divinylbenzene copolymers, graphitized carbon, silica- and polymer-based ion-exchangers, or metal-loaded sorbent [61, 63, 64].

Sample processing in SPE involves four distinct steps [65]:

\section{1) Conditioning of sorbent.}

Before use, the solid phase must be conditioned with the appropriate solvent in order to improve the reproducibility of analyte retention. The functional groups of the particleloaded membranes must be solvated and thus activated. Also in this step, the unwanted matrix impurities of the sorbent, cartridges and disks arising from their manufacture must be eliminated in order to minimize contaminations [66]. Next, the conditioning solvent is rinsed from the sorbent with the same solvent as the sample solvent (or a similar solvent with respect to polarity, $\mathrm{pH}$ and ion activity). During this process, care must be taken that the sorbent does not dry out, in order to achieve a high and reproducible recovery rate.

\section{2) Retention or sorption step.}

The analyte sample will be applied by means of a small vacuum or pressure, and through this process the analyte will be retained by the sorbent and thus preconcentrated. The flow rate should be small enough to warrant maximal retention.

3) Optional washing step.

After the sample has been processed, the solid sorbent is rinsed with a weak solvent to displace unwanted matrix 
components from the sorbent material without displacing the analytes.

\section{4) Desorption or elution step.}

The analytes of interest are eluted from the sorbent with a small volume of an appropriate solvent for subsequent chemical analysis. Care must be taken that the unwanted matrix components are retained on the sorbent. A drop-bydrop elution (percolation) is an ideal way to achieve a high recovery rate. It is also advisable to use several smaller portions instead of just one large portion.

\section{Experimental SPE conditions}

For the preconcentration of organic acids in snow samples, the SPE cartridges used in this work contained a strong anion exchange (SAX) material. The retention of the analytes relies on the electrostatic interaction between one or more negatively charged functional groups of the analytes and the positively charged functional group of the sorbent.

The retention mechanism of the SAX cartridges is well suited to the preconcentration of organic acids, since it is possible to retain ionic species with very different polarities. Furthermore, nonionic compounds which are also in the snow samples are not retained by the SAX cartridges and therefore do not cause problems in the subsequent MS analysis.

The SPE-SAX material used in this study and supplied by the firm Supelco (Bellefonte, PA, USA) contains an aliphatic quaternary amine group that is covalently bonded over a short alkyl chain to a silica surface (see Fig. 1). A quaternary amine is a strong base and exists as positively charged cation that exchanges or attracts anionic species in the contacting solution-thus the term "strong anion exchanger."

Silica has the advantage of being very pressure-stable, and it does not shrink nor swell upon contact with organic solvents. The silica gel base material consists of $50-\mu \mathrm{m}$ irregularly shaped particles with a $70-\AA ̊$ pore diameter. Strong anion exchange is very well suited to aqueous matrices with low salt contents $(<0.1 \mathrm{M})$ and the extraction of carboxylic acids, which would not otherwise be sufficiently bonded because of their weakly acidic character.

The functional groups of the sorbent and analyte must be available in a charged state to achieve an efficient electrostatic retention mechanism. The $\mathrm{p} K_{\mathrm{a}}$ of a quaternary amine is very high (greater than 14). It is permanently
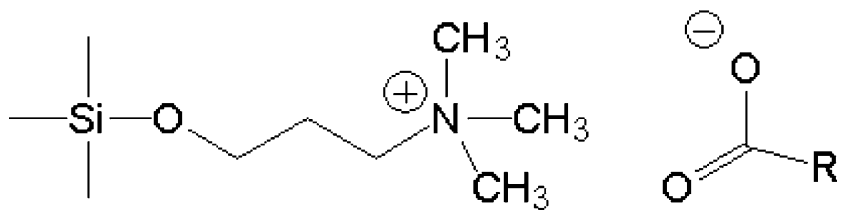

Fig. 1 Retention mechanism employed by the SPE-SAX sorbent charged at all $\mathrm{pHs}$ in aqueous solution. As a result, SPE$\mathrm{SAX}$ is used to isolate strong anionic (very low $\mathrm{p} K_{\mathrm{a}},<1$ ) or weak anionic (moderate low $\mathrm{pK}_{\mathrm{a}},>2$ ) compounds, as long as the $\mathrm{pH}$ of the sample is sufficiently high so that the compound of interest is charged.

During the retention step, the $\mathrm{pH}$ value of the analyte solution should lie two $\mathrm{pH}$ units above the first $\mathrm{p} K_{\mathrm{a}}$ value of the dicarboxylic acid, whereas during the elution the $\mathrm{pH}$ value should remain two units below the second $\mathrm{p} K_{\mathrm{a}}$ value of the analyte. The latter compounds then reside in their neutral form and are no longer bonded to the sorbent material.

The SAX-filled cartridges were first conditioned with a certain amount of methanol depending on the cartridge size and sorbent mass: $5 \mathrm{~mL} \mathrm{CH} \mathrm{CH}_{3} \mathrm{OH}$ for $100 \mathrm{mg}$ sorbent, and $50 \mathrm{~mL} \mathrm{CH}_{3} \mathrm{OH}$ for $1 \mathrm{~g}$ sorbent. Next, they were rinsed with $10 \mathrm{~mL}$ or $50 \mathrm{~mL} \mathrm{H}_{2} \mathrm{O}$, respectively. During this step, the solid-phase sorbent was not completely dried. The analyte was sucked at a flow rate of $5 \mathrm{~mL} / \mathrm{min}$ through the solid phase, which was then dried under a slight vacuum for 10 $\mathrm{min}$. To elute the analytes from the sorbent, small volumes ( $2 \mathrm{~mL}$ or $4 \mathrm{~mL}$, respectively) of $0.1 \mathrm{~N} \mathrm{HCl}$ solutions were forced, using a slight overpressure of purified $\mathrm{N}_{2}$, through the sorbent. The flow rate remained at about $0.7-1.0 \mathrm{~mL} /$ min. The extracted analytes were collected in screw-cap vials and stored at $4{ }^{\circ} \mathrm{C}$. The analysis by LC/MS occurred within 36 hours of the extraction.

\section{LC/MS-TOF analysis}

The separation of the analytes was performed with highpressure liquid chromatography (HPLC). One hundred microliters of the SPE extract were directly injected into the HPLC system, which consisted of a thermostated autosampler (Series 200, Perkin Elmer, Norwalk, CT, USA), a degasser and a quaternary pump (both 1100 Series, Agilent Technologies, Heilbronn, Germany). The analytical column was a ReproSil-Pur $\mathrm{C}_{18}$-AQ $(250 \mathrm{~mm} \times$ $2 \mathrm{~mm}$ I.D., $5 \mu \mathrm{m}$ particle size) in a stainless steel cartridge (Dr. Maisch GmbH, Ammerbuch, Germany).

"Large volume injection" is possible due to the low organic content of the eluent at the beginning of the chromatographic procedure. Its low solvent strength leads to a focusing of the analytes at the beginning and thus to preconcentration on the column. The authors chose $100 \mu \mathrm{L}$ as the injection volume because it is possible to take advantage of the preconcentrating effect while the volume is still sufficiently small in order to ensure a linear response with respect to concentration. The described gradient has already previously been successfully applied to the quantification of oxodicarboxylic acids [67].

The vials were kept in the autosampler at $7{ }^{\circ} \mathrm{C}$ by means of a Peltier cooler. A $0.2 \mu \mathrm{m}$ prefilter prevented the 
analytical column from being plugged by particles arising from the injected samples.

The eluents were $0.1 \%$ formic acid in water (eluent A) and acetonitrile (eluent B). The gradient of the mobile phase was as follows: $0 \% \mathrm{~B}$ from 0 to $0.5 \mathrm{~min}$, gradient to $15 \%$ B from 0.5 to $4 \mathrm{~min}$, gradient to $95 \%$ B from 4 to $20 \mathrm{~min}$, gradient to $0 \% \mathrm{~B}$ from 20 to $23 \mathrm{~min}$, and isocratic $0 \%$ B from 23 to $29 \mathrm{~min}$. The flow rate was kept at $400 \mu \mathrm{L} /$ min. The role of $\mathrm{HCOOH}$ was to reduce the $\mathrm{pH}$ of the eluent, so that the dicarboxylic acids remained undissociated in their molecular form. This improved the resolution of the chromatographic separation.

The HPLC system was coupled to a hybrid mass spectrometer (quadrupole and time-of-flight) QSTAR (Applied Biosystems MDS SCIEX, Toronto, Canada) by an electrospray ion source. This instrument combines tandem mass spectrometry (MS/MS) with the high mass resolution of a time-of-flight detector (TOF). The mass accuracy was below $10 \mathrm{ppm}$. For mass calibration, the authentic standard compounds glutaric acid $\left(\mathrm{C}_{5}\right.$-di) and tridecanedioic acid $\left(\mathrm{C}_{13}\right.$-di) were used to calibrate the mass spectrometer internally. The electrospray source was operated in the negative mode (ESI-) at $400{ }^{\circ} \mathrm{C}$ and an ionization voltage of $-4 \mathrm{kV}$.

\section{Materials}

To calibrate and evaluate the analytical system, the following standards (with their abbreviations and stated purities given in parenthesis) were used: glutaric acid $\left(\mathrm{C}_{5}\right.$-di, $\left.99 \%\right)$, adipic acid ( $\mathrm{C}_{6}$-di, $\left.99 \%\right)$, suberic acid $\left(\mathrm{C}_{8}\right.$-di, $\left.98 \%\right)$, decanedioic acid $\left(\mathrm{C}_{10}\right.$-di, $\left.99 \%\right)$, dodecanedioic acid $\left(\mathrm{C}_{12}\right.$-di, $\left.99 \%\right)$, tridecanedioic acid $\left(\mathrm{C}_{13}\right.$-di, $\left.99 \%\right)$, pinic acid $(98 \%)$, pinonic acid (98\%) and phthalic acid (Ph, 99.5\%) from Sigma-Aldrich (Steinheim, Germany); pimelic acid $\left(\mathrm{C}_{7}-\mathrm{di},>99 \%\right)$, and azelaic acid $\left(\mathrm{C}_{9}\right.$-di, $\left.>99 \%\right)$ from Fluka (Buchs, Switzerland). To condition the solid phase ("gradient grade") and prepare standard solutions, ("hyper-grade") methanol from Merck (Darmstadt, Germany) was used. The SPE, DSC-SAX cartridges were obtained from Supelco with $20 \mu \mathrm{m}$-fritted disks made of polyethylene. Water was purified with Purelab Ultra (Vivendi, Ransbach-Baumbach, Germany), with a rest resistance of $18.2 \mathrm{M} \Omega$. The eluents, water (with added $0.1 \%$ $\mathrm{HCOOH}$ ) and acetonitrile, for the HPLC system were supplied by Riedel de Haën (Selze, Germany).

\section{Results}

Laboratory experiments and method development

The main objective of this work was to develop one analytical procedure that could quantify as many compounds as possible using only one extraction method. Since the compounds differ substantially in their physical properties (e.g., solubility, polarity), it was not possible to optimize the recovery for every single compound with the same procedure. Hence, the described method represents a compromise between the demand for high recoveries and its applicability to a broad range of compounds.

\section{Optimization of the SPE method}

In the initial phase of the optimization of the SPE method, the recovery rates of the solid-phase extraction method for standard solutions of dicarboxylic acids were determined. The first attempts at elution were performed with solutions of $1.0 \mathrm{~N} \mathrm{HCl}$. These strongly acidic solutions caused problems with the LC/MS analysis. During the chromatographic separation, a strong background signal was observed at the masses $\mathrm{m} / \mathrm{z} 160.93,162.93,164.93,195.92$, 197.92, 199.92 and 201.92, producing peaks with signal intensities comparable to those produced by the individual analytes. This can be observed in Fig. 2, where the total ion chromatogram (TIC, Fig. 2a) of the extract of a standard solution is shown together with the extracted ion chromatogram (XIC, Fig. 2b) for the suberic acid anion $(\mathrm{m} / \mathrm{z}=$ 173). The complete mass spectrum in the retention time range from 10.6 to $10.9 \mathrm{~min}$ is displayed in Fig. 2c, showing the background signals and the analyte $(\mathrm{m} / \mathrm{z}=173)$.

The probable cause of the strong background signal is a hydrolysis reaction on the stationary phase of the HPLC column, which is catalyzed by $\mathrm{HCl}$. This evidence is based on the observation that the background peaks were no longer visible after flushing the column with HCI-free solutions for a few hours. If the observed mass peaks were impurities in the $\mathrm{HCl}$ solutions, they would have been detected as single peaks, and not during the whole record of the chromatogram. Tests where the concentration of $\mathrm{HCl}$ was varied showed that the background mass spectral peaks increased in proportion to the $\mathrm{HCl}$ concentration.

The hydrolysis products that were released from the column caused a decrease in the ionization efficiency of the ESI with respect to the analytes. This effect considerably reduced the sensitivity of the mass spectrometer. At elevated background levels, the relationship between peak area and concentration was found to depart from linearity for dicarboxylic acid concentrations larger than $1.0 \mu \mathrm{mol} / \mathrm{L}$. At reduced background levels, however, linearity was found to hold for dicarboxylic acid concentrations up to $10 \mu \mathrm{mol} / \mathrm{L}$.

The decrease in the ionization efficiency of the analytes is related to the electrochemical character of the electrospray ionization. It could be considered a special form of a redox reaction, where in the negative ESI mode those compounds that possess the highest redox potential are ionized [68]. After 
Fig. 2 a Total ion chromatogram (TIC) of a standard solution of dicarboxylic acids; $\mathbf{b}$ extracted ion chromatogram (XIC) of mass $m / z 173$ for suberic acid; c complete mass spectrum at retention time 10.6 10.9 min. The observed background signals are explained in the main text

\section{a)}

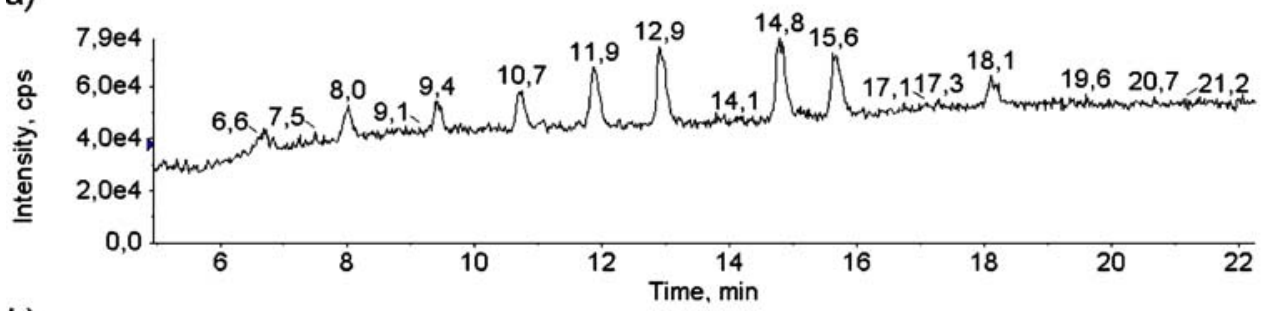

b)

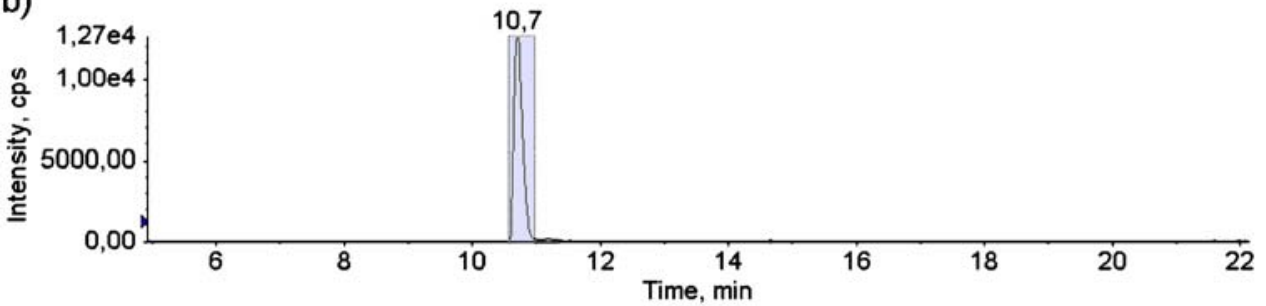

c)

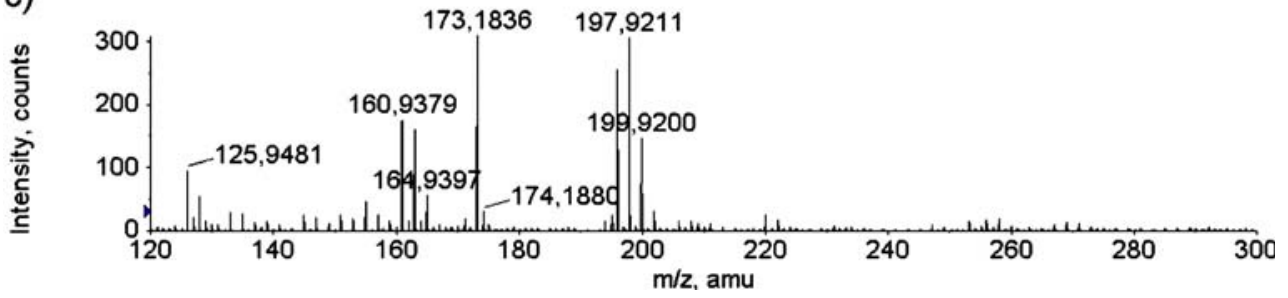

all of the molecules of that class have been ionized, then the compounds with the second highest redox potential are ionized, and so on. The greatest number of ions formed per unit time is limited by the electrical current, however, and not by the flow rate. The nonlinear effects observed during the calibration indicate that the compounds released from the HPLC column possess a higher redox potential than the analytes, and are therefore preferentially ionized. Consequently, the dynamic range of the mass spectrometer is strongly reduced. The dynamic range is defined as the concentration range over which the response factor $R_{\mathrm{F}}$ is independent of the analyte concentration.

\section{Recovery rates of authentic standards}

Optimization of the flow rate Initially, the effect of the flow rate on the recovery rate during the extraction was investigated. The manufacturer of the cartridges advised that a maximum flow rate of $5 \mathrm{~mL} / \mathrm{min}$ should be used, whereas for the ion exchange products a maximum flow rate of $2 \mathrm{~mL} / \mathrm{min}$ was recommended.

This would have caused very long extraction times of several hours for molten snow sample volumes of $500 \mathrm{~mL}$. Recovery rates were measured for aqueous standard solutions of a series of dicarboxylic acids with identical concentrations of $5 \mathrm{nmol} / \mathrm{L}$. By inserting a throttle valve between the membrane pump and the cartridge, the subpressure and thus the flow rate could be regulated. This setup allowed us to estimate the number of droplets that passed through the extraction column. The flow rate could be adjusted between
2.4 and $9.0 \mathrm{~mL} / \mathrm{min}$. The recovery rates are summarized in Table 1. No significant reductions in the recovery rates of the analyzed compounds were observed for the higher flow rates. Further extractions were therefore carried out with flow rates of between $2 \mathrm{~mL} / \mathrm{min}$ and $4 \mathrm{~mL} / \mathrm{min}$.

Effect of the $\mathrm{HCl}$ concentration The hydrochloric acid used for the extraction caused the hydrolysis of the column material, but at the same time a strong inorganic acid is needed for the elution of the analytes. Hence the concentration of hydrochloric acid was reduced to $0.1 \mathrm{~mol} / \mathrm{L}$. The background levels in the mass spectra were considerably reduced upon lowering the $\mathrm{HCl}$ concentration from $1 \mathrm{~N}$ to $0.1 \mathrm{~N}$. The recovery rates for the dicarboxylic acids were nearly identical for both $\mathrm{HCl}$ concentrations up to a chain length of twelve carbon atoms (dodecanedioic acid). For tridecanedioic acid, a drop of $9 \%$ was noted. The recovery rates for $0.1 \mathrm{~N} \mathrm{HCl}$ solutions and the ratio between the recovery rates for 0.1 and $1 \mathrm{~N}$ solutions are presented in

Table 1 Recovery rates of linear dicarboxylic acids at different flow rates during extraction

Flow rate $\quad \mathrm{C}_{5}$-di $\quad \mathrm{C}_{6}$-di $\quad \mathrm{C}_{7}$-di $\mathrm{C}_{8}$-di $\mathrm{C}_{9}$-di $\mathrm{C}_{10}$-di $\mathrm{C}_{11}$-di $\mathrm{C}_{12}$-di $\left(\mathrm{mL} \min ^{-1}\right)$

\begin{tabular}{lllllllll}
\hline 2.4 & 85 & 103 & 90 & 81 & 72 & 72 & $61^{1}$ & 30 \\
3.8 & 71 & 100 & 81 & 65 & 62 & 63 & $66^{1}$ & 33 \\
6.2 & 71 & 101 & 85 & 71 & 71 & 75 & $70^{1}$ & 39 \\
9.0 & 71 & 102 & 80 & 65 & 62 & 74 & $59^{1}$ & 35 \\
\hline
\end{tabular}

1 Interpolated 
Table 2. A further reduction in the $\mathrm{HCl}$ concentration to $0.05 \mathrm{~mol} / \mathrm{L}$ gave recovery rates of $60 \%$ or less without lowering significantly the background level. For this reason a $\mathrm{HCl}$ concentration of $0.1 \mathrm{~mol} / \mathrm{L}$ was chosen for the elution of the analytes.

In order to assess the overall reproducibility of the analytical procedure, four extractions of authentic standards were conducted. The recovery rates of the authentic standards and their standard deviations were determined, as displayed in Table 2. Standard deviations for all compounds were between 1.4 and $4.8 \%$. The precision of the analytical method is thus about $5 \%$.

The decrease in the recovery rates of linear dicarboxylic acids is probably caused by the increasing chain length beyond dodecanedioic acid $\left(\mathrm{C}_{12}\right.$-di), which results in increasing nonpolar interactions between the alkyl chain of the dicarboxylic acid and the solid phase (SAX). Attempts were undertaken to reduce this effect by mixing in $15 \%$ methanol. However, the added methanol caused asymmetry and broadening of the peaks in the chromatogram, so further elutions were performed without the addition of organic solvent. The limit of detection for each compound was calculated as three times the standard deviation of the background noise of the extracted ion chromatogram baseline from a solution of standards. The recovery rates of the $\mathrm{C}_{8}$ to $\mathrm{C}_{13}$ dicarboxylic acids could be fitted by a quadratic function $\left(R^{2}=0.9979\right)$.

It should be noted that the recovery rates for $\mathrm{C}_{12}$-di in Table 2 are about a factor two lower than the values in Table 1. The optimization of the flow rate was performed a few weeks prior to the measurements cited in Table 2. The differences between the recovery rates in Tables 1 and 2 are attributed to an improved elution procedure where the $0.1 \mathrm{~N}$ $\mathrm{HCl}$ solution was added in four small portions rather than one. Each portion of solution was allowed to wet the sorbent for 1 min prior to being forced into the screw-cap vial by overpressure. This resulted in higher recovery rates for most analytes, especially for the higher dicarboxylic acids $\left(>\mathrm{C}_{8}\right)$.

Breakthrough volume The breakthrough volume was checked by conducting extractions with two cartridges in a series with sample volumes of 600 and $1000 \mathrm{~mL}$ with a flow-rate of $\sim 4 \mathrm{~mL} / \mathrm{min}$. The analytes were then extracted and quantified as described previously in the text. It was found that the analytes were only retained on the first cartridge and that no breakthrough to the second cartridge was observed. Hence, it can be stated that the breakthrough volume is larger than $1000 \mathrm{~mL}$.

Table 2 Analytical information for the organic acids used in this study

\begin{tabular}{|c|c|c|c|c|c|c|c|c|}
\hline Compound & $\begin{array}{l}\text { Mass of } \\
\text { molecularion } \\
\text { (u) }\end{array}$ & $\begin{array}{l}\text { Retention } \\
\text { time } \\
(\mathrm{min})\end{array}$ & $\begin{array}{l}\text { RSD of } \\
\text { Retention } \\
\text { time }(\%)\end{array}$ & $\begin{array}{l}\text { Detection } \\
\text { limit } \\
(\mathrm{nmol} / \mathrm{L})\end{array}$ & $\begin{array}{l}\text { Quantification } \\
\text { limit (nmol/L) }\end{array}$ & $\begin{array}{l}\text { Recovery } \\
\text { rate } 0.1 \mathrm{~N} \\
\mathrm{HCl}(\%)\end{array}$ & $\begin{array}{l}\text { Standard } \\
\text { deviation } \\
(\%)\end{array}$ & $\begin{array}{l}\text { Ratio of recovery } \\
\text { rates }(0.1 \mathrm{~N} / 1 \mathrm{~N} \\
\mathrm{HCl})\end{array}$ \\
\hline $\begin{array}{l}\text { Glutaric acid } \\
\left(\mathrm{C}_{5} \text {-di) }\right.\end{array}$ & 131.0310 & 6.7 & 1.9 & 11.8 & 39.6 & 65 & 3.8 & 1.13 \\
\hline $\begin{array}{l}\text { Adipic acid } \\
\left(\mathrm{C}_{6}-\mathrm{di}\right)\end{array}$ & 145.0450 & 8.0 & 0.5 & 8.2 & 27.3 & 102 & 1.9 & 1.07 \\
\hline $\begin{array}{l}\text { Pimelic acid } \\
\left(\mathrm{C}_{7}-\mathrm{di}\right)\end{array}$ & 159.0584 & 9.4 & 0.2 & 6.9 & 22.9 & 92 & 4.8 & 1.02 \\
\hline $\begin{array}{l}\text { Suberic acid } \\
\left(\mathrm{C}_{8} \text {-di) }\right.\end{array}$ & 173.0718 & 10.7 & 0.1 & 4.0 & 15.4 & 76 & 1.4 & 1.10 \\
\hline $\begin{array}{l}\text { Azelaic acid } \\
\left(\mathrm{C}_{9} \text {-di) }\right.\end{array}$ & 187.0879 & 11.9 & 0.1 & 1.3 & 4.3 & 79 & 1.6 & 1.08 \\
\hline $\begin{array}{l}\text { Sebacic acid } \\
\left(\mathrm{C}_{10}-\mathrm{di}\right)\end{array}$ & 201.1021 & 13.0 & 0.1 & 1.9 & 6.1 & 77 & 4.9 & 1.11 \\
\hline $\begin{array}{l}\text { Undecanedioic } \\
\text { acid }\left(\mathrm{C}_{11} \text {-di) }\right.\end{array}$ & 215.2306 & $13.8^{1}$ & 0.1 & 0.6 & 2.0 & $71^{1}$ & - & - \\
\hline $\begin{array}{c}\text { Dodecanedioic } \\
\text { acid }\left(\mathrm{C}_{12} \text {-di) }\right.\end{array}$ & 229.1300 & 14.8 & 0.1 & 0.9 & 3.0 & 61 & 3.5 & 0.97 \\
\hline $\begin{array}{l}\text { Tridecanedioic } \\
\text { acid }\left(\mathrm{C}_{13}-\mathrm{di}\right)\end{array}$ & 243.1414 & 15.7 & 0.4 & 2.5 & 8.3 & 41 & 2.4 & 0.91 \\
\hline $\begin{array}{l}\text { Phthalic acid } \\
(\mathrm{Ph})\end{array}$ & 165.0090 & 9.48 & 0.3 & 9.6 & 32.0 & 83 & 1.8 & - \\
\hline Pinonic acid & 183.0844 & 11.3 & - & 29.5 & 98.2 & 74 & 3.0 & - \\
\hline Pinic acid & 185.0629 & 10.1 & - & 103.9 & 346.4 & 53 & 3.5 & - \\
\hline
\end{tabular}

Detection and quantification limits refer to the concentrations in the extract

1 Interpolated 


\section{Identification of the analytes}

The identification of the detected peaks in snow samples was based on a comparison of the retention times of the peaks in the selected ion chromatogram (XIC) with the retention times of authentic standards. A summary of the identified compounds in snow is given in Table 2, together with the calibrated mass of the quasi ion $(\mathrm{M}-\mathrm{H})^{-}$, the retention time, and its relative standard deviation (RSD) for real samples.

Figure 3 shows typical extracted ion chromatograms of the target species in a standard solution, illustrating the efficiency of the chromatographic separation of the acids. The retention time increases with the chain length of the dicarboxylic acids due to the decreasing polarity with chain length. Since no standard was available for undecanedioic acid, the retention time was interpolated by linear regression, with the square of the correlation coefficient being $R^{2}=0.99$.

\section{Quantification of the analytes}

Standard solutions were prepared for every analyte by dissolving 7-10 $\mathrm{mg}$ in $5 \mathrm{~mL}$ methanol (hyper-grade). The mass was determined by exact weighing to an accuracy of $10^{-5} \mathrm{~g}$. Aliqouts $(80-220 \mu \mathrm{L})$ of these methanolic solutions were then pipetted in a $10 \mathrm{~mL}$ volumetric flask which was then filled to the calibration mark with ultrapure water. The amount of the aliquot was chosen so as to obtain a stock solution with a concentration of $100 \mu \mathrm{mol} / \mathrm{L}$ of each compound.

The stock solution was then diluted with ultrapure water to obtain standard solutions of $100 \mathrm{nmol} / \mathrm{L}, 250 \mathrm{nmol} / \mathrm{L}$, $500 \mathrm{nmol} / \mathrm{L}$, and $1000 \mathrm{nmol} / \mathrm{L}$, which were analyzed using the HPLC-ESI-MS method. The square of the correlation coefficient $\left(R^{2}\right)$ was $>0.99$ for all linear calibration curves, showing that the response of the instrument is directly proportional to the concentration of the compound. All concentrations of the extracts from the snow samples analyzed in this work were in this dynamic range of concentrations.

For every $\mathrm{m} / \mathrm{z}$ value of each analyte and for each concentration, the area of the peak was determined by integration using the software Analyst QS.

The response factor $R_{\mathrm{F}}$ is defined as the ratio of the peak area $P A$ to the concentration $c$ :

$R_{\mathrm{F}}=\frac{\text { Peak area } P A}{\text { Concentration } c}$

The response factors were determined for each analyte by the linear regression of plots of peak area versus concentration. The response factors are plotted in Fig. 4 for a series of dicarboxylic acids with carbon chain lengths ranging from $\mathrm{C}_{8}$ to $\mathrm{C}_{13}$. The linear regression of this plot enabled the determination of $R_{\mathrm{F}}=42.3$ for undecanedioic acid $\left(\mathrm{C}_{11}\right.$-di). As can be seen, the response factors increase with increasing chain length, and thus with decreasing polarity and solubility of the dicarboxylic acids. This observation can be explained by the equilibrium-partitioning model [69].

The quantification limit was calculated as ten times the standard deviation of the background noise of a solution of authentic standard compounds. The values are summarized in Table 1.

\section{Field measurement}

Snow sampling was performed in December 2006 and January 2007 in the area of the Fee glacier, Switzerland $\left(44^{\circ} 7^{\prime} \mathrm{N}, 7^{\circ} 55^{\prime} \mathrm{E}\right)$ at heights of between 3056 and $3580 \mathrm{~m}$

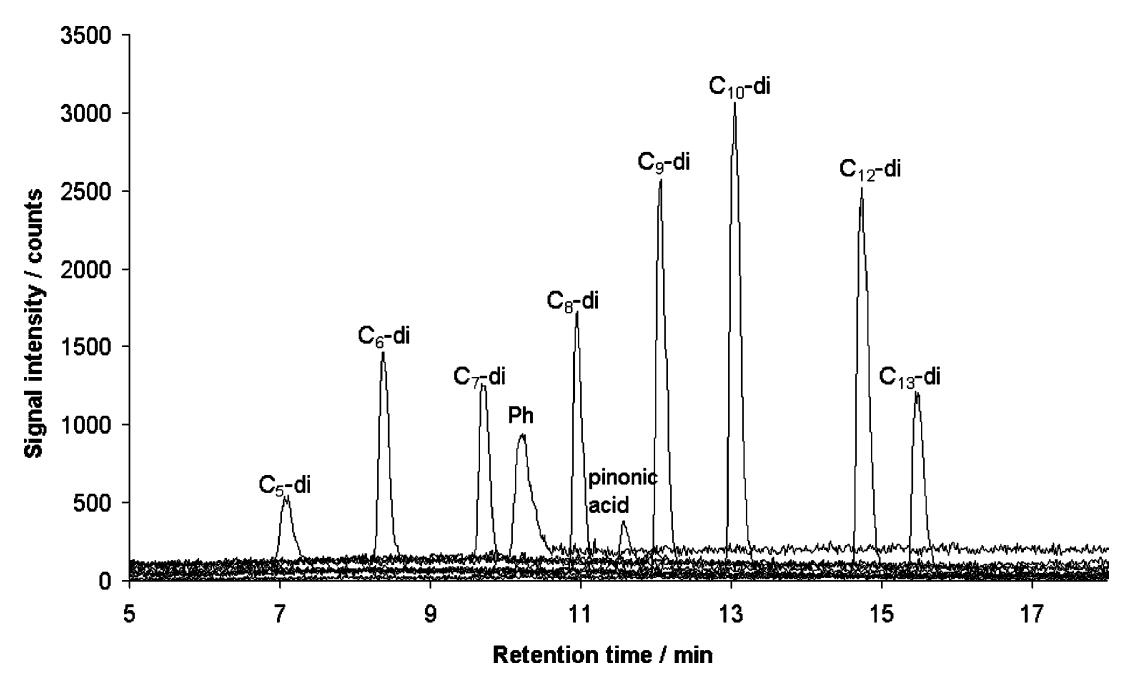

Fig. 3 Superposition of the individual extracted ion chromatograms for the analytes from a standard solution (the peak from pinic acid is not visible due to its low height) 


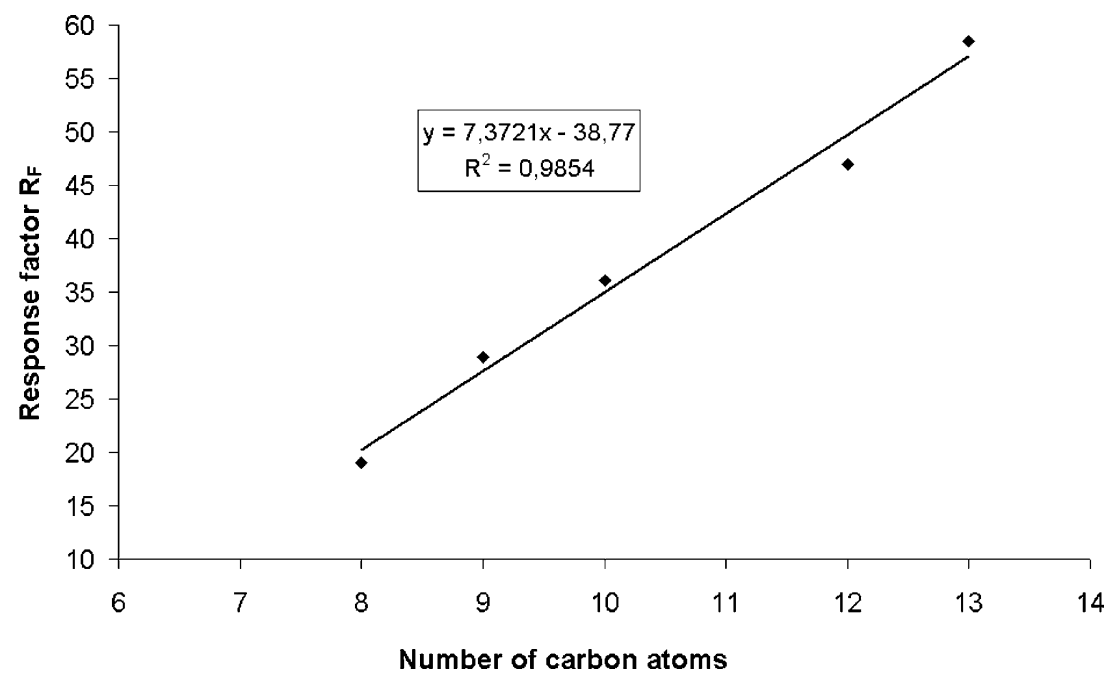

Fig. 4 Response factors of dicarboxylic acids as a function of chain length

asl. The snow samples were collected using a shovel made of polypropylene and then transferred to 2-L precleaned glass containers (soda lime glass, Wheaton) with PTFEcoated polypropylene caps. The containers were stored at $-18{ }^{\circ} \mathrm{C}$ in darkness until analysis. The volumes of the molten snow samples were between 200 and $500 \mathrm{~mL}$. Information on the samples, snow and ambient temperatures, sample locations and depths, and snow fall histories are given in Table 3.

The individual samples along with sampling times, depth of sampling and dicarboxylic acid concentrations are summarized in Table 4. Their compositions are also presented graphically in Fig. 5. Most samples were collected from the top layer; however, samples were also taken from various depths up to $80 \mathrm{~cm}$. A homologous series of the dicarboxylic acids $\left(\mathrm{C}_{5}\right.$ to $\left.\mathrm{C}_{12}\right)$ and phthalic acid were identified and quantified in the samples.
The molecular distributions of the dicarboxylic acids presented in this study are consistent with the distributions reported previously in the literature (see Table 5). Generally, glutaric acid $\left(\mathrm{C}_{5}\right.$-di) was the most abundant (mean $3.90 \mathrm{nmol} / \mathrm{L})$, followed by adipic acid $\left(\mathrm{C}_{6}-\mathrm{di}, 3.35 \mathrm{nmol} / \mathrm{L}\right)$ and phthalic acid $(\mathrm{Ph}, 3.04 \mathrm{nmol} / \mathrm{L})$. The concentrations of pimelic $\left(\mathrm{C}_{7}\right.$-di) and suberic acid $\left(\mathrm{C}_{8}\right.$-di) were usually considerably lower, while azelaic acid $\left(\mathrm{C}_{9}\right.$-di) was the fourth most abundant $(2.12 \mathrm{nmol} / \mathrm{L})$. The concentrations of the higher homologous dicarboxylic acids $\left(>\mathrm{C}_{9}\right.$-di) decrease rapidly with chain length and were one or two orders of magnitude lower $(0.09-0.47 \mathrm{nmol} / \mathrm{L})$ than than those of glutaric acid. Tridecanedioic acid $\left(\mathrm{C}_{13}\right.$-di), pinonic acid and pinic acid were detected in the samples but could not be quantified due to their low concentrations.

The mean concentrations presented in this study range between the concentrations found in the remote (Alert) and

Table 3 Information on the snow samples collected at the Fee glacier

\begin{tabular}{|c|c|c|c|c|c|c|c|}
\hline Date & Time & $\begin{array}{l}\text { Height } \\
\text { asl (m) }\end{array}$ & $\begin{array}{l}T_{\text {air }} \\
\left({ }^{\circ} \mathrm{C}\right)\end{array}$ & $\begin{array}{l}T_{\text {snow }} \\
\left({ }^{\circ} \mathrm{C}\right)\end{array}$ & Remarks & Layer & $\begin{array}{l}\text { Number of } \\
\text { samples }\end{array}$ \\
\hline 18.12 .2006 & $10: 30$ & 3580 & -13 & -16 & Snowfall event from 09.12.2006 (about $65 \mathrm{~cm}$ ) & $\begin{array}{l}\text { Surface layer } \\
-20 \text { to }-50 \mathrm{~cm}\end{array}$ & $\begin{array}{l}4 \\
4\end{array}$ \\
\hline 19.12.2006 & $10: 45$ & 3580 & -13 & -20 & Snowfall event from 09.12.2006 (about $65 \mathrm{~cm}$ ) & $\begin{array}{l}-40 \text { to }-60 \mathrm{~cm} \\
-60 \text { to }-80 \mathrm{~cm}\end{array}$ & $\begin{array}{l}4 \\
4\end{array}$ \\
\hline 21.12 .2006 & $10: 00$ & 3580 & -12 & -18 & Snowfall event from 09.12.2006 (about $65 \mathrm{~cm}$ ) & Surface (loose) & 8 \\
\hline 22.12 .2006 & $9: 45$ & 3580 & -14 & -18 & Snowfall event from 09.12.2006 (about $65 \mathrm{~cm}$ ) & $\begin{array}{l}\text { Surface (compact) } \\
\text { Surface (loose) }\end{array}$ & $\begin{array}{l}4 \\
4\end{array}$ \\
\hline 23.01 .2007 & $\begin{array}{l}10: 30 \\
10: 45 \\
11: 00 \\
\mathbf{1 2 : 3 0} \\
\mathbf{1 3 : 0 0}\end{array}$ & $\begin{array}{l}3460 \\
3290 \\
3056 \\
\mathbf{3 3 4 0} \\
\mathbf{3 0 5 6}\end{array}$ & $\begin{array}{l}-3 \\
-3 \\
-3\end{array}$ & $\begin{array}{l}-4 \\
-7 \\
-4\end{array}$ & Snow fall since 22.01 .2007 18:00 & $\begin{array}{l}\text { Surface layer } \\
\text { Surface layer } \\
\text { Surface layer } \\
\text { Surface layer } \\
\text { Surface layer }\end{array}$ & $\begin{array}{l}4 \\
4 \\
3 \\
5 \\
5\end{array}$ \\
\hline 25.01 .2007 & $14: 30$ & 3570 & -14 & -20 & Snowfall event from 24.01.2007 & $\begin{array}{l}0 \text { to }-5 \mathrm{~cm} \\
-10 \text { to }-30 \mathrm{~cm}\end{array}$ & $\begin{array}{l}4 \\
4\end{array}$ \\
\hline
\end{tabular}


Table 4 Concentrations (in nmol/L) of dicarboxylic acids in molten snow; the values in parentheses denote the standard deviations of multiple samples $(n=4$ to 8$)$ at each location

\begin{tabular}{|c|c|c|c|c|c|c|c|c|c|c|}
\hline $\begin{array}{l}\text { Sampling time, location } \\
\text { and snow depth }\end{array}$ & $\mathrm{C}_{5}$-di & $\mathrm{C}_{6}$-di & $\mathrm{C}_{7}$-di & $\mathrm{C}_{8}$-di & $\mathrm{C}_{9}$-di & $\mathrm{C}_{10}$-di & $\mathrm{C}_{11}$-di & $\mathrm{C}_{12}$-di & $\mathrm{Ph}$ & Total acids \\
\hline $\begin{array}{l}\text { 18.12.2006, } 3580 \mathrm{~m}, \\
\text { surface layer }\end{array}$ & $7.0(0.9)$ & $2.8(0.2)$ & $1.1(0.2)$ & $1.5(0.2)$ & $2.3(0.7)$ & $0.3(0.1)$ & $0.3(<0.1)$ & $0.1(<0.1)$ & $3.5(0.3)$ & 18.8 \\
\hline $\begin{array}{l}18.12 .2006,3580 \mathrm{~m} \\
20-50 \mathrm{~cm}\end{array}$ & $6.8(0.9)$ & $2.3(0.7)$ & $1.2(0.2)$ & $1.4(0.4)$ & $2.0(0.6)$ & $0.2(0.1)$ & $0.1(0.1)$ & $<0.1(<0.1)$ & $3.7(0.5)$ & 17.8 \\
\hline $\begin{array}{l}19.12 .2006,3580 \mathrm{~m} \\
40-60 \mathrm{~cm}\end{array}$ & $1.0(<0.1)$ & $1.8(0.8)$ & $0.6(0.1)$ & $1.0(0.1)$ & $2.1(0.3)$ & $0.21(0.07)$ & $0.2(0.1)$ & $0.1(<0.1)$ & $0.4(<0.1)$ & 7.2 \\
\hline $\begin{array}{l}19.12 .2006,3580 \mathrm{~m}, \\
60-80 \mathrm{~cm}\end{array}$ & $2.1(<0.1)$ & $1.4(0.4)$ & $0.6(0.3)$ & $0.7(0.4)$ & $1.6(0.5)$ & $0.2(0.1)$ & $0.10(0.1)$ & $<0.1(<0.1)$ & $0.5(0.1)$ & 7.1 \\
\hline $\begin{array}{l}\text { 21.12.2006, } 3580 \mathrm{~m}, \\
\text { surface (loose) }\end{array}$ & $5.8(0.5)$ & $5.3(1.7)$ & $0.9(0.1)$ & $1.1(0.6)$ & $0.8(0.6)$ & $0.3(0.2)$ & $0.2(0.1)$ & $0.1(0.1)$ & $3.3(2.8)$ & 17.8 \\
\hline $\begin{array}{l}22.12 .2006,3580 \mathrm{~m}, \\
\text { surface (compact) }\end{array}$ & $4.0(0.4)$ & $2.0(0.4)$ & $0.8(0.1)$ & $1.2(0.3)$ & $2.9(1.0)$ & $0.2(<0.1)$ & $0.3(0.2)$ & $<0.1(<0.01)$ & $1.9(0.2)$ & 13.1 \\
\hline $\begin{array}{l}\text { 22.12.2006, } 3580 \mathrm{~m}, \\
\text { surface (loose) }\end{array}$ & $0.6(0.4)$ & $2.6(0.1)$ & $0.2(<0.1)$ & $0.4(0.3)$ & $0.9(0.1)$ & $0.1(<0.1)$ & $0.1(<0.1)$ & $0.1(<0.1)$ & $1.4(0.5)$ & 6.3 \\
\hline $\begin{array}{l}23.01 .2007,3460 \mathrm{~m}, \\
\text { surface }\end{array}$ & $20.6(0.4)$ & $6.1(0.3)$ & $1.4(0.1)$ & $3.7(0.8)$ & $4.9(0.5)$ & $1.2(0.6)$ & $0.2(<0.1)$ & $0.2(0.1)$ & $1.9(0.1)$ & 21.8 \\
\hline $\begin{array}{l}23.01 .2007,3290 \mathrm{~m}, \\
\text { surface }\end{array}$ & $2.7(0.2)$ & $3.3(0.2)$ & $0.8(0.6)$ & $2.0(<0.1)$ & $2.3(0.2)$ & $0.6(<0.1)$ & $0.2(0.2)$ & $0.1(0.1)$ & $4.1(0.8)$ & 16.2 \\
\hline $\begin{array}{l}23.01 .2007,3056 \mathrm{~m}, \\
\text { surface }\end{array}$ & $1.6(0.3)$ & $3.5(0.2)$ & $1.2(<0.1)$ & $1.3(0.2)$ & $2.0(0.3)$ & $0.3(<0.1)$ & $0.2(0.1)$ & $0.1(<0.1)$ & $4.9(0.6)$ & 15.1 \\
\hline $\begin{array}{l}23.01 .2007,3340 \mathrm{~m}, \\
\text { surface }\end{array}$ & $6.6(0.3)$ & $2.4(0.7)$ & $0.5(0.1)$ & $5.7(5.9)$ & $1.2(0.1)$ & $2.2(1.3)$ & $0.7(<0.1)$ & $0.1(<0.1)$ & $5.7(3.1)$ & 25.1 \\
\hline $\begin{array}{l}23.01 .2007,3056 \mathrm{~m}, \\
\text { surface }\end{array}$ & $6.1(0.3)$ & $6.4(1.6)$ & $0.7(0.2)$ & $2.1(0.5)$ & $2.1(0.1)$ & $0.2(0.1)$ & $0.2(0.1)$ & $0.1(<0.1)$ & $2.1(0.7)$ & 19.9 \\
\hline $\begin{array}{l}25.01 .2007,3570 \mathrm{~m} \\
0-5 \mathrm{~cm}\end{array}$ & $4.6(1.9)$ & $5.4(1.1)$ & $2.6(0.7)$ & $3.3(0.5)$ & $3.9(0.3)$ & $0.6(<0.1)$ & $0.4(<0.1)$ & $0.2(0.1)$ & $6.0(0.1)$ & 26.8 \\
\hline $\begin{array}{l}25.01 .2007,3570 \mathrm{~m}, \\
10-30 \mathrm{~cm}\end{array}$ & $3.6(1.9)$ & $1.6(0.6)$ & $0.5(0.2)$ & $0.4(0.3)$ & $0.8(0.4)$ & $0.1(<0.1)$ & $<0.1(<0.1)$ & $0.1(0.1)$ & $3.3(0.7)$ & 10.5 \\
\hline Mean value & $3.9(2.1)$ & $3.4(1.6)$ & $0.9(0.6)$ & $1.8(1.4)$ & $2.1(1.1)$ & $0.5(0.6)$ & $0.2(0.2)$ & $0.1(0.1)$ & $3.0(1.2)$ & $16.0(6.1)$ \\
\hline
\end{tabular}

Fig. 5 Compositions of higher dicarboxylic acids in the snow samples collected at the Fee Glacier

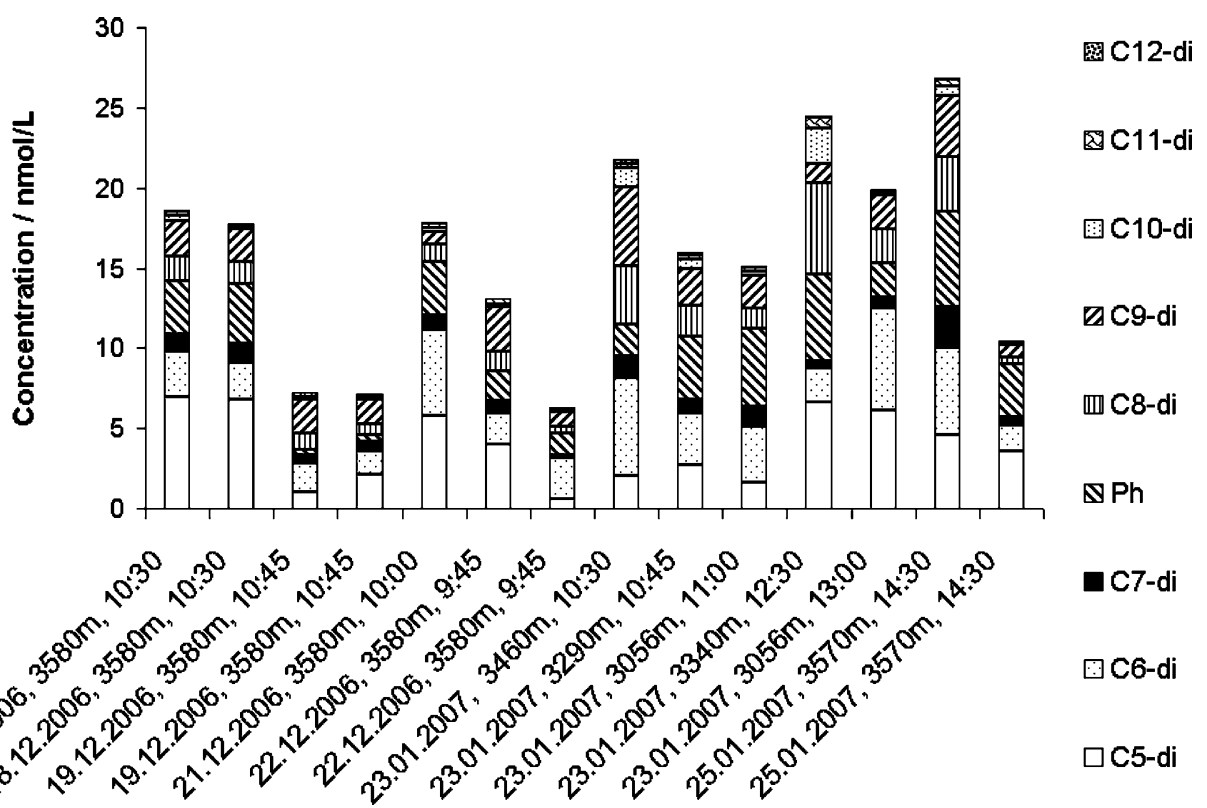


Table 5 Concentrations $(\mathrm{nmol} / \mathrm{L})$ of dicarboxylic acids in snow from urban and remote locations

\begin{tabular}{|c|c|c|c|c|c|c|c|c|c|c|}
\hline & \multicolumn{3}{|c|}{$\begin{array}{l}\text { Fee glacier, Switzerland } \\
\text { Dec 2006/Jan } 2007\end{array}$} & \multicolumn{3}{|c|}{$\begin{array}{l}\text { Alert, Arctic [28] } \\
\text { Feb } 2000\end{array}$} & \multicolumn{2}{|c|}{$\begin{array}{l}\text { Tokyo, Japan } \\
\text { [29] 18.Mar } 1992\end{array}$} & \multicolumn{2}{|c|}{$\begin{array}{l}\text { Sapporo, Japan } \\
\text { [30] Feb } 2003\end{array}$} \\
\hline & Min & Max & Mean & Min & Max & Mean & Min & Max & 19/20 Feb & $26 \mathrm{Feb}$ \\
\hline Glutaric acid $\left(\mathrm{C}_{5}\right.$-di) & 0.6 & 7.0 & 3.9 & 1.1 & 5.1 & 4.3 & 4.8 & 12.1 & 78.5 & 14.8 \\
\hline Adipic acid $\left(\mathrm{C}_{6}\right.$-di) & 0.5 & 6.1 & 3.4 & 1.5 & 12.7 & 2.9 & 6.4 & 21.0 & 38.3 & 9.5 \\
\hline Pimelic acid $\left(\mathrm{C}_{7}\right.$-di) & 0.2 & 2.6 & 0.9 & 0.1 & 0.4 & 0.4 & 0.9 & 4.6 & & \\
\hline Suberic acid $\left(\mathrm{C}_{8}\right.$-di) & 0.4 & 5.9 & 1.8 & 0.2 & 0.8 & 0.5 & 4.4 & 6.6 & 12.6 & 2.0 \\
\hline Azelaic acid $\left(\mathrm{C}_{9}\right.$-di) & 4.9 & 3.9 & 2.1 & 0.6 & 2.5 & 1.9 & 4.5 & 61.1 & 46.8 & 11.8 \\
\hline Sebacic acid $\left(\mathrm{C}_{10}\right.$-di) & 0.1 & 1.2 & 0.5 & $<0.1$ & 0.2 & 0.2 & & & & \\
\hline Undecanedioic acid $\left(\mathrm{C}_{11}\right.$-di) & $<0.1$ & 0.3 & 0.2 & 0.1 & 0.1 & 0.1 & & & & \\
\hline Dodecanedioic acid $\left(\mathrm{C}_{12}\right.$-di) & $<0.1$ & 0.2 & 0.1 & & & & & & & \\
\hline Phthalic acid $(\mathrm{Ph})$ & 0.4 & 6.0 & 3.0 & 2.8 & 19.1 & 6.6 & 13.5 & 24.5 & 111.4 & 50.0 \\
\hline
\end{tabular}

urban locations (Tokyo, Sapporo), but are closer to those reported from the remote sampling sites. All dicarboxylic acids exhibit a high variability of concentration, depending on the sample site and time (see Fig. 6). Air masses originating from different locations (continental or marine air) at the site prior to sampling are likely to be influential. The reason for the high variability of concentrations on the 23rd January 2007 with respect to the sampling site could not be determined. A strong influence of local primary or secondary sources cannot, however, be ruled out.

\section{Top layer samples}

The concentration of each acid as well as the total concentration show a high variability with respect to time and location of sampling. The most abundant acids were usually glutaric, adipic and azelaic acids. It has been proposed that glutaric and adipic acid are predominantly formed in the atmosphere by the photooxidation of polycyclic aromatic hydrocarbons [11] and cyclic alkenes [40], and are thus mainly of anthropogenic origin. The concentrations of the higher dicarboxylic acids are generally lower, except for azelaic acid. The latter is formed in the atmosphere by ozonolysis of long-chain biogenic fatty acids [70] such as oleic $\left(\mathrm{C}_{18} \mathrm{H}_{34} \mathrm{O}_{2}\right)$ and linolenic acid $\left(\mathrm{C}_{18} \mathrm{H}_{32} \mathrm{O}_{2}\right)$. Both of these acids have a double bond after the ninth carbon atom, the ozonolysis of which leads to the formation of azelaic acid [71].

\section{Samples from depth}

Samples from various depths within the snow layer were taken on the 18th/19th December 2006 and 25th January 2007. On these days, samples were taken not only from the top layer but also from depths of 10-30, 20-50, 40-60, and $/$ or $60-80 \mathrm{~cm}$, respectively.

The samples from the surface layer and the samples from $20-50 \mathrm{~cm}$ show almost the same concentrations. The two

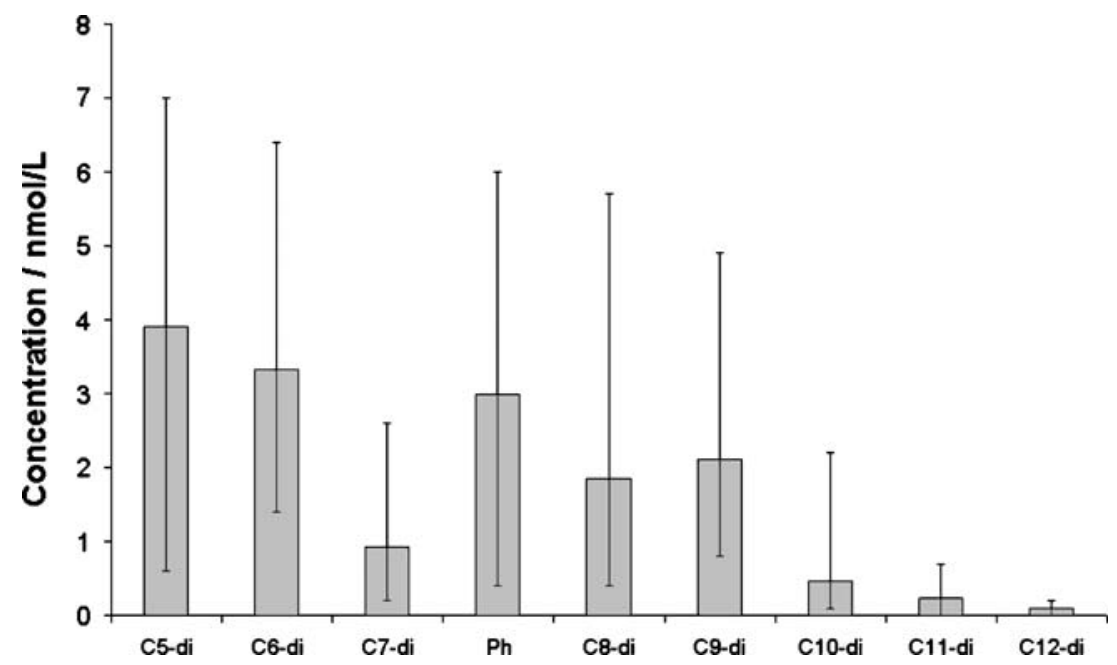

Fig. 6 Mean values of dicarboxylic acid concentrations; error bars represent the minimum and maximum values found in the snow samples 
samples from $40-80 \mathrm{~cm}$ also show similar compositions, although the total concentration is less than $50 \%$ of that in the two layers above. A possible explanation for this effect could be dry deposition and sublimation of the snow. Both processes would lead to higher dicarboxylic acid contents. Since the snowfall event took place on the 9th December 2006 , it is also possible that diffusion of acid particles occurred within the layer, which would explain the constant composition throughout the first two layers.

The samples taken in January 2007 exhibit far more pronounced variations in concentration with respect to sample depth. The acid concentration decreased by $38 \%$ in the $10-30 \mathrm{~cm}$ layer as compared to the surface layer composition. The snow was only present for roughly 24 hours before being sampled, so there was not enough time for aerosol particle diffusion into the snow.

\section{Conclusions}

We have described the development and the optimization of a solid-phase extraction method that is well suited to the quantification of higher linear dicarboxylic acids, phthalic acid, and pinonic acid in snow samples.

The recovery rates were determined using solutions of authentic standards and found to be in the range of $41-102 \%$, while the reproducibility of the overall method was very good (standard deviation $\sim 5 \%$ ). The background signal during the mass spectrometric quantification was substantially lowered by using $0.1 \mathrm{~N} \mathrm{HCl}$ during the elution step, thus increasing the linear range of the method to at least $10 \mu \mathrm{mol} / \mathrm{L}$.

The method was successfully applied to snow samples collected from the Fee glacier in Switzerland. The homologous aliphatic $\alpha, \omega$-dicarboxylic acids from $C_{5}$ to $C_{12}$ and phthalic acid could be quantified, and a high variability in concentration between different sampling sites, times and depths was observed.

The observed high variability may be explained by the different back trajectories of the air masses which arrived at the Fee glacier prior to sampling and the different histories of the snow of different depths within the snow layer. Indeed sunlight, temperature, and oxidation potential of the atmosphere (by $\mathrm{OH}$ radicals and ozone) may have influenced the concentrations of the different dicarboxylic acids collected.

Acknowledgement We gratefully acknowledge the funding of this work by the Deutsche Forschungsgemeinschaft (DFG) as part of the collaborative research centre (Sonderforschungsbereich) Die troposphärische Eisphase (SFB 641).

Open Access This article is distributed under the terms of the Creative Commons Attribution Noncommercial License which permits any noncommercial use, distribution, and reproduction in any medium, provided the original author(s) and source are credited.

\section{References}

1. Jacobson MC, Hansson HC, Noone KJ, Charlson RJ (2000) Rev Geophys 38:267-294

2. Andreae MO, Gelencsér A (2006) Atmos Chem Phys 6:3131-3148

3. Pöschl U (2005) Angew Chem Int Ed 44:7520-7540

4. Rogge WF, Mazurek MA, Hildemann LM, Cass GR, Simoneit BRT (1993) Atmos Environ 27A:1309-1330

5. Sempéré R, Kawamura K (2003) Global Biogeochem Cy 17:1069

6. Saxena P, Hildemann LM (1996) J Atmos Chem 24:57-109

7. Baboukas ED, Kanakidou M, Mihalopoulos N (2000) J Geophys Res 105:14459-14471. doi:10.1029/1999JD900977

8. Limbeck A, Puxbaum H (2000) J Geophys Res 105:1985719867. doi:10.1029/2000JD900123

9. Limbeck A, Puxbaum H, Otter L, Scholes MC (2001) Atmos Environ 35:1853-1862

10. Kawamura K, Steinberg S, Kaplan IR (1996) Atmos Environ 30:1035-1052

11. Kawamura K, Ikushima K (1993) Environ Sci Technol 27:22272235

12. Lawrence J, Koutrakis P (1996) J Geophys Res 101:9171-9184. doi:10.1029/95JD03357

13. Röhrl A, Lammel G (2002) Chemosphere 46:1195-1199

14. Alves C, Carvalho A, Pio C (2002) J Geophys Res 107:8345. doi:10.1029/2001JD000616

15. Kubátová A, Vermeylen R, Claeys M, Cafmeyer J, Maenhaut W (2002) J Geophys Res 107:8343. doi:10.1029/2001JD000556

16. Limbeck A, Puxbaum H (1999) Atmos Environ 33:1847-1852

17. Legrand M, Preunkert S, Galy-Lacaux C, Liousse C, Wagenbach D (2005) J Geophys Res 110:D13302. doi:10.1029/ 2004JD005515

18. Limbeck A, Kraxner Y, Puxbaum H (2005) J Aerosol Sci 36:9911005

19. Edney EO, Kleindienst TE, Conver TS, McIver CD, Corse EW, Weathers WS (2003) Atmos Environ 37:3947-3965

20. Kawamura K, Sakaguchi F (1999) J Geophys Res 104:35013509. doi:10.1029/1998JD100041

21. Mochida M, Kawabata A, Kawamura K, Hatsushika H, Yamazaki K (2003) J Geophys Res 108:4193

22. Kawamura K, Kasukabe H, Barrie LA (1996) Atmos Environ 30:1709-1722

23. Kawamura K, Seméré R, Imai Y, Fujii Y, Hayashi M (1996) J Geophys Res 101:18721-18728. doi:10.1029/96JD01541

24. Sempéré R, Kawamura K (1996) Atmos Environ 30:1609-1619

25. Kawamura K, Kasukabe H, Yasui O, Barrie LA (1995) Geophys Res Lett 22:1253-1256

26. Narukawa M, Kawamura K, Anlauf KG, Barrie LA (2003) J Geophys Res 108:4575. doi:10.1029/2003JD003646

27. Grannas AM, Shepson PB, Filley TR (2004) Global Biogeochem Cy 18:1006. doi:10.1029/2003GB002133

28. Narukawa M, Kawamura K, Li S-M, Bottenheim JW (2002) Atmos Environ 36:2491-2499

29. Sempéré R, Kawamura K (1994) Atmos Environ 28:449-459

30. Kawamura K, Watanabe T (2004) Anal Chem 76:5762-5768

31. Sheesley RJ, Schauer JJ, Bean E, Kenski D (2004) Environ Sci Technol 38:6491-6500

32. Legrand M, Preunkert S, Oliveira T, Pio CA, Hammer S, Gelencsér A, Kasper-Giebl A, Laj P (2007) J Geophys Res 112: D23S07. doi:10.1029/2006JD008019

33. Lefer BL, Talbot RW, Harriss RC, Bradshaw JD, Sandholm ST, Olson JO, Sachse GW, Collins J, Shipham MA, Blake DR, Klemm KI, Klemm O, Gorzelska K, Barrick J (1994) J Geophys Res 99:1721-1737. doi:10.1029/93JD02091

34. Legrand M, DeAngelis M (1996) J Geophys Res 101:4129-4145. doi:10.1029/95JD03296 
35. Narukawa M, Kawamura K, Takeuchi N, Nakajima T (1999) Geophys Res Lett 26:3101-3104

36. Gao S, Hegg DA, Hobbs PV, Kirchstetter TW, Magi BI, Sadilek M (2003) J Geophys Res 108:8491. doi:10.1029/2002JD002324

37. Graham B, Mayol-Bracero OL, Guyon P, Roberts GC, Decesari S, Facchini MC, Artaxo P, Maenhaut W, Koll P, Andreae MO (2002) J Geophys Res 107:8047. doi:10.1029/2001JD000336

38. Schauer JJ, Rogge WF, Hildemann LM, Mazurek MA, Cass GR, Simoneit BR (1996) Atmos Environ 30:3837-3855

39. Stephanou EG, Stratigakis NE (1993) J Chromatography 644:141-151

40. Hatakeyama S, Ohno M, Weng JH, Tagake H, Akimoto H (1987) Environ Sci Technol 21:52-57

41. Boy M, Petaja T, Dal Maso M, Rannik U, Rinne J, Aalto P, Laaksonen A, Vaattovaara P, Joutsensaari J, Hoffmann T, Warnke J, Apostolaki M, Stephanou EG, Tsapakis M, Kouvarakis A, Pio C, Carvalho A, Rompp A, Moortgat G, Spirig C, Guenther A, Greenberg J, Ciccioli P, Kulmala M (2004) Atmos Chem Phys 4:657-678

42. Hatakeyama S, Izumi K, Fukuyama T, Akimoto H (1989) J Geophys Res 94:13013-13024. doi:10.1029/89JD00816

43. Christoffersen TS, Hjorth J, Horie O, Jensen NR, Kotzias D, Molander LL, Neeb P, Ruppert L, Winterhalter R, Virkkula A, Wirtz K, Larsen BR (1998) Atmos Environ 32:1657-1661

44. Glasius M, Lahaniati M, Calogirou A, Di Bella D, Jensen NR, Hjorth J, Kotzias D, Larsen BR (2000) Environ Sci Technol 34:1001-1010

45. Winterhalter R, Neeb P, Grossmann D, Kolloff A, Horie O, Moortgat G (2000) J Atmos Chem 35:165-197

46. Koch S, Winterhalter R, Uherek E, Kolloff A, Neeb P, Moortgat GK (2000) Atmos Environ 34:4031-4042

47. Larsen BR, Di Bella D, Glasius M, Winterhalter R, Jensen NR, Hjorth J (2001) J Atmos Chem 38:231-276

48. Pio C, Alves C, Duarte A (2001) Atmos Environ 35:389-401

49. Yu JZ, Griffin RJ, Cocker DR, Flagan RC, Seinfeld JH, Blanchard P (1999) Geophys Res Lett 26:1145-1148

50. Kavouras IG, Mihalopoulos N, Stephanou EG (1999) Geophys Res Lett 26:55-58
51. Jaoui M, Kleindienst TE, Lewandowski M, Offenberg JH, Edney EO (2005) Environ Sci Technol 39:5661-5673

52. Novakov T, Penner JE (1993) Nature 365:823-826

53. Fuzzi S, Andreae MO, Huebert BJ, Kulmala M, Bond TC, Boy M, Doherty SJ, Guenther A, Kanakidou M, Kawamura K, Kerminen VM, Lohmann U, Russell LM, Pöschl U (2006) Atmos Chem Phys 6:2017-2038

54. Hartz KEH, Tischuk JE, Chan MN, Chan CK, Donahue NM, Pandis SN (2006) Atmos Environ 40:605-617

55. Sun JM, Ariya PA (2006) Atmos Environ 40:795-820

56. Prenni AJ, DeMott PJ, Kreidenweis SM, Sherman DE, Russell LM, Ming Y (2001) J Phys Chem 105:11240-11248

57. Cruz CN, Pandis SN (1997) Atmos Environ 31:2205-2214

58. Kumar PP, Broekhuizen K, Abbatt JPD (2003) Atmos Chem Phys 3:509-520

59. Hori M, Ohta S, Murao N, Yamagata S (2003) J Aerosol Sci 34:419-448

60. Zobrist B, Marcolli C, Koop T, Luo BP, Murphy DM, Lohmann U, Zardini AA, Krieger UK, Corti T, Cziczo DJ, Fueglistaler S, Hudson PK, Thomson DS, Peter T (2006) Atmos Chem Phys 6:3115-3129

61. Berrueta LA, Gallo B, Vicente F (1995) Chromatographia 40:474-483

62. Hennion MC (1991) Trends Anal Chem 10:317-323

63. Hennion MC (1999) J Chromatogr A 856:3-54

64. Liška I (2000) J Chromatogr A 885:3-16

65. Poole CF, Gunatilleka AD, Sethuraman R (2000) J Chromatogr A $885: 17-39$

66. Junk GA, Avery MJ, Richard JJ (1988) Anal Chem 60:1347-1350

67. Römpp A, Winterhalter R, Moortgat GK (2006) Atmos Environ 40:6846-6862

68. Rohner TC, Lion N, Girault HH (2004) Phys Chem Chem Phys 6:3056-3068

69. Enke CG (1997) Anal Chem 69:4885-4893

70. Stephanou EG, Stratigakis NE (1993) Environ Sci Technol 27:1403-1407. doi:10.1021/ES00044A016

71. Yokouchi Y, Ambe Y (1986) Atmos Environ 20:1727-1734 